\title{
THE EFFECT OF SILICA FUME ON THE DURABILITY OF MAGNESIUM OXYCHLORIDE CEMENT
}

\author{
QING HUANG*, **,***, JING WEN*, **, YING LI*,**, WEIXIN ZHENG*, **, ***, CHENGGONG CHANG*, **, \\ JINMEI DONG*, **, YANGYANG MAN*, **, ***, DANCHUN*, **, ***, AYUAN ZHOU*, **, "XUEYING XIAO*, ** \\ *Key Laboratory of Comprehensive and Highly Efficient Utilization of Salt Lake Resources, Qinghai Institute of Salt Lakes, \\ Chinese Academy of Sciences, No. 18, Xinning Road, Xining 810008, P.R. China \\ **Key Laboratory of Salt Lake Resources Chemistry of Qinghai Province, No. 18, Xinning, Xining 810008, P.R .China \\ ***University of Chinese Academy of Sciences, No. 19, Yuquan Road, Beijing 100049, P.R. China \\ "E-mail: xueyingxiao012@163.com
}

Submitted January 8, 2019; accepteApril 25, 2019

\begin{abstract}
Keywords: Magnesium oxychloride cement, Nano-silica, Water resistance, Silica fume, Phosphoric acid
This paper investigated the water resistance of magnesium oxychloride cement (MOC) incorporating silica fume + phosphoric acid + nano-silica $(S P N)$. Strength retention was tested to evaluate the water resistance of MOC. The characterisation of the hydration products and the microstructure of the typical samples before and after water immersion were carried out by using $X$-ray diffraction (XRD) and scanning electron microscope (SEM) facilities. The results show that incorporation of SPN significantly enhances the water resistance of MOC. The generation of an insoluble magnesium-chloride-silicate-hydrate gel and a magnesium-chloride-hydrate gel and the densification of the microstructure contribute to the remarkable improvement in the water resistance of MOC. Meanwhile, the pore structure results show that the total porosity and permeability of MOC has no direct relevant relationship on the improvement of the water resistance at the time of 28-day air curing.
\end{abstract}

\section{INTRODUCTION}

Magnesium oxychloride cement, also known as Sorel's cement, is a potential cementitious material to be used for many applications in construction such as fire protection [1], grinding wheels $[2,3]$ and industrial flooring [4] due to its ability to gain strength rapidly and to withstand abrasion and high temperatures [1,5]. Additionally, MOC does not need wet curing and can provide high early strength [6].

However, previous literature has indicated that the compressive strength of MOC decreased significantly by about $90 \%$ when soaked in water for 28 days. The main reason is due to the decomposition of the hydration products $3 \mathrm{Mg}(\mathrm{OH})_{2} \cdot \mathrm{MgCl}_{2} \cdot 8 \mathrm{H}_{2} \mathrm{O}$ (Phase 3 ) and $5 \mathrm{Mg}(\mathrm{OH})_{2}$ $\cdot \mathrm{MgCl}_{2} \cdot 8 \mathrm{H}_{2} \mathrm{O}$ (Phase 5) which progressively decompose to $\mathrm{Mg}(\mathrm{OH})_{2}$ with little ability, thus, leading to the apparent decrease in the compressive strength [5], as shown in Equation 1 and 2. Therefore, the common application of MOC is limited to indoor environments by its poor water resistance. It then becomes urgent to overcome the above problem by trying all kinds of means. Researchers have put forward some effective additives to improve the water resistance, among which adding water-soluble phosphate has been considered to be a simple and efficient method. It was proposed that the compressive strength of MOC soaked in water for 28 days decreased by only $10 \%$ and $15 \%$ when adding $1 \%$ soluble phosphates [7] and $30 \%$ fly ash, respectively [5]. It is believed that the main reason is the transformation from a crystalline to a gel- like Phase 5 for the improved water resistance of MOC when adding phosphates [8]. The water resistance was already improved by adding various reported additives, while the strength retention coefficient also decreased after water immersion in MOC. Therefore, if the water resistance of MOC increased with the increasing water immersion time, it will make a great breakthrough in the application of MOC.

$$
\begin{aligned}
& 5 \mathrm{Mg}(\mathrm{OH})_{2} \cdot \mathrm{MgCl}_{2} \cdot 8 \mathrm{H}_{2} \mathrm{O}= \\
& =5 \mathrm{Mg}(\mathrm{OH})_{2}+\mathrm{Mg}^{2+}+2 \mathrm{Cl}^{-}+8 \mathrm{H}_{2} \mathrm{O} \\
& 3 \mathrm{Mg}(\mathrm{OH})_{2} \cdot \mathrm{MgCl}_{2} \cdot 8 \mathrm{H}_{2} \mathrm{O}= \\
& =3 \mathrm{Mg}(\mathrm{OH})_{2}+\mathrm{Mg}^{2+}+2 \mathrm{Cl}^{-}+8 \mathrm{H}_{2} \mathrm{O}
\end{aligned}
$$

In recent years, with the innovation of nanotechnology, the nano-modification of cement-based materials has attracted much research interest. The use of nano materials in Portland concrete is gaining more importance owing to its better properties in the fresh and hardened states of the concrete. Some of the nanosized materials used are nano- $\mathrm{SiO}_{2}$, nano- $\mathrm{TiO}_{2}$, nano$\mathrm{Fe}_{2} \mathrm{O}_{3}$, nano- $\mathrm{Al}_{2} \mathrm{O}_{3}$, and carbon nanotubes/fibres. Among all the nanomaterials, nano-silica is the most widely used material in cement and concrete to improve the performance, because of its pozzolanic reactivity besides its pore-filling effect. It is reported that the addition of nano-silica can accelerate the hydration process and also reacts with calcium hydroxide and produces more amounts of calcium-silicate-hydrates thereby improving the mechanical properties [9]. Concretes incorporated 
with nano-silica also result in a denser and more compact microstructure with a smaller amount of calcium hydroxide crystals [10-14]. Pozzolanic reactivity is found to be much higher and quicker in nano-silica added concrete [11]. Besides, the incorporation of nanosilica in concrete results in a higher compressive strength $[10,15-18]$. Nano-modification is the manipulation of the structure on a nanoscale (less than $100 \mathrm{~nm}$ ) to develop cement composites that exhibit enhanced or novel properties and functions. However, existing research is entirely limited to ordinary Portland cement and concrete. There are no experimental studies on nanomaterials incorporated in MOC. Simultaneously, none of the research has investigated the effect of nanosilica on water resistance with regards to MOC.

Therefore, in this paper, using the experience of nano-technology in Portland cement for reference, the influence of nano-silica on the water resistance of MOC was studied, in order to improve the microstructure of $\mathrm{MOC}$, thus, to enhance the water resistance of MOCbased materials. Furthermore, for MOC containing silica fume + phosphoric acid, with the further addition of $1 \%$ nano-silica, we hope to produce a new high-performance cement with much better water resistance.

\section{EXPERIMENTAL}

Raw materials

The MOC was prepared by mixing amounts of light-burned magnesia powder $(\mathrm{MgO})$ and bischofite $\left(\mathrm{MgCl}_{2} \cdot 6 \mathrm{H}_{2} \mathrm{O}\right)$, which were obtained from the Liaoning and Qinghai provinces in China, respectively. The lightburned magnesia powder with a content of active $\mathrm{MgO}$ $55.4 \%$ (by weight), was tested at $105^{\circ} \mathrm{C}$ and $101.3 \mathrm{KPa}$ by the direct hydration method [19]. Aggregate silica fume and modifiers, such as phosphoric acid $\left(\mathrm{H}_{3} \mathrm{PO}_{4}\right)$ and nano-silica were adopted in this experiment, which were produced from a local power plant, Shanghai Macklin Biochemical Co. Ltd and Sinopharm Group, respectively. The chemical analysis of the raw materials used is shown in Table 1. The specific surface of the silica fume is $10.1 \mathrm{~m}^{2} \cdot \mathrm{g}^{-1}$ measured by the BET method. The particle size of the nano-silica was $30 \pm 5 \mathrm{~nm}$ with a purity of $99.5 \%$ and its specific surface is $640 \mathrm{~m}^{2} \cdot \mathrm{g}^{-1}$.
Sample preparation

Cement paste specimens with a size of $20 \times 20 \times$ $20 \mathrm{~mm}$ were produced with an active $\mathrm{MgO} / \mathrm{MgCl}_{2}$ molar ratio of 7 and an $\mathrm{H}_{2} \mathrm{O} / \mathrm{MgCl}_{2}$ molar ratio of 15 [20, 21]. Table 2 shows the mix proportions of the cement paste prepared. To prepare the MOC specimens, bischofite was first dissolved into water before mixing with lightburned magnesia powder. Then, the prepared fresh slurry with $15 \%$ silica fume, $1 \% \mathrm{H}_{3} \mathrm{PO}_{4}$ and $1 \%$ nano-silica additives by the light-burnt magnesia powder weight were cast in steel moulds through vibration compaction. The fresh samples were covered with a plastic sheet to avoid evaporation and initially cured for $24 \mathrm{~h}$ at room temperature. The specimens were then removed from the moulds and cured in an environmental chamber at $20 \pm 3{ }^{\circ} \mathrm{C}$ and $50 \% \mathrm{RH}$ for air curing.

The compressive strength of the mixtures was recorded at 3-day, 7-day, and 28-day intervals after air curing and at 28-day and 56-day intervals after water immersion. The strength retention was used to evaluate the water resistance by comparing the compressive strength of the MOC before water immersion for 28 days and after immersion for 28 days and 56 days. Identification of the crystalline structure of the samples was characterised by X-ray diffraction (XRD). The mineralogy and microstructure were studied by using scanning electron microscopy (SEM). The detailed test procedures can be found in previous literature [20, 21]. The pore structure was investigated by using mercury intrusion porosimetry (MIP, AutoPore IV 9500) [22].

Table 2. The recipe of the MOC paste.

\begin{tabular}{lccc}
\hline $\begin{array}{l}\text { Code } \\
\text { name }\end{array}$ & $\begin{array}{c}\text { Silica fume } \\
(\%)\end{array}$ & $\begin{array}{c}\mathrm{H}_{3} \mathrm{PO}_{4} \\
(\%)\end{array}$ & $\begin{array}{c}\text { Nano-silica } \\
(\%)\end{array}$ \\
\hline P0 & 0 & 0 & 0 \\
N01 & 0 & 0 & 1 \\
S15 & 15 & 0 & 0 \\
H15 & 15 & 1 & 0 \\
I15 & 15 & 1 & 1 \\
\hline
\end{tabular}

Table 1. Chemical compositions of the raw materials used.

\begin{tabular}{llllcccc}
\hline \multirow{2}{*}{ light-burnt magnesia } & Components & $\mathrm{MgO}$ & $\mathrm{CaO}$ & $\mathrm{Al}_{2} \mathrm{O}_{3}$ & $\mathrm{SiO}_{2}$ & $\mathrm{Fe}_{2} \mathrm{O}_{3}$ & LOI (Loss on ignition) \\
& Mass fraction (\%) & 85.96 & 1.29 & 1.28 & 6.03 & 0.57 & 4.78 \\
\hline \multirow{2}{*}{ bischofite } & Components & $\mathrm{MgCl}_{2}$ & $\mathrm{KCl}$ & $\mathrm{NaCl}$ & $\mathrm{CaCl}_{2}$ & $\mathrm{MgSO}_{4}$ & Water insoluble \\
& Mass fraction (\%) & 46.43 & 0.21 & 0.36 & 0.01 & 0.02 & 0.07 \\
\hline \multirow{2}{*}{ silica fume } & Components & $\mathrm{SiO}_{2}$ & $\mathrm{Al}_{2} \mathrm{O}_{3}$ & $\mathrm{Fe}_{2} \mathrm{O}_{3}$ & $\mathrm{MgO}$ & $\mathrm{K}_{2} \mathrm{O}$ & Others \\
& Mass fraction (\%) & 86.74 & 0.72 & 2.29 & 2.88 & 3.36 & 4.01 \\
\hline
\end{tabular}




\section{RESULTS AND DISCUSSION}

\section{Compressive strength}

Figure 1 illustrates the compressive strength development of the different types of MOC cured in air for 28 days. It is apparent that the compressive strength of the blended paste decreased with an increase in the replacement ratio of the additives, which is consistent with the previous results [5]. Other researchers have also found that additives reduce the strength of MOC before 28 days [7]. For instance, the compressive strength of $\mathrm{P} 0, \mathrm{~S} 15, \mathrm{H} 15$, and I15 are $119.2 \mathrm{MPa}, 100 \mathrm{MPa}, 104 \mathrm{MPa}$, and 105.5 $\mathrm{MPa}$ after 28-day air curing, respectively. There are two possible reasons for that: (1) the replacement of $\mathrm{MgO}$ decreased the quantity of the main hydration product, especially with the addition of silica fume; (2) the higher water absorption of the phosphoric acid allows less water to be available for hydration, thus, it retards the crystal growth in MOC pastes. But it is noteworthy that the incorporation of the nano-silica in MOC has a $5.50 \%$ (I15) and $1.44 \%$ (I15) higher compressive strength than the S15 and $\mathrm{H} 15$ and $2.35 \%$ (N01) higher than the P0 samples. As a result, early age strength is slightly enhanced due to the incorporation of the nano-silica.

With the incorporation of nano-silica, the strength gain of the cement-based materials can be improved due to its hydration seeding effect that activates the silica fume and high pozzolanic activity [18, 23-25], which may result in the higher generation of a magnesium-chloridesilicate-hydrate gel ( $\mathrm{M}-\mathrm{Cl}-\mathrm{S}-\mathrm{H}$ gel) and a magnesiumchloride-hydrate gel (M-Cl-H gel) and a more densified bulk structure. Then the higher compressive strength of N01 over P0 is mainly attributed to the hydration seeding effect and high pozzolanic activity of the nanosilica that acts as a nucleator to prompt the formation of the main strength hydration in MOC. Additionally, it has been reported that nano-particles are thought to

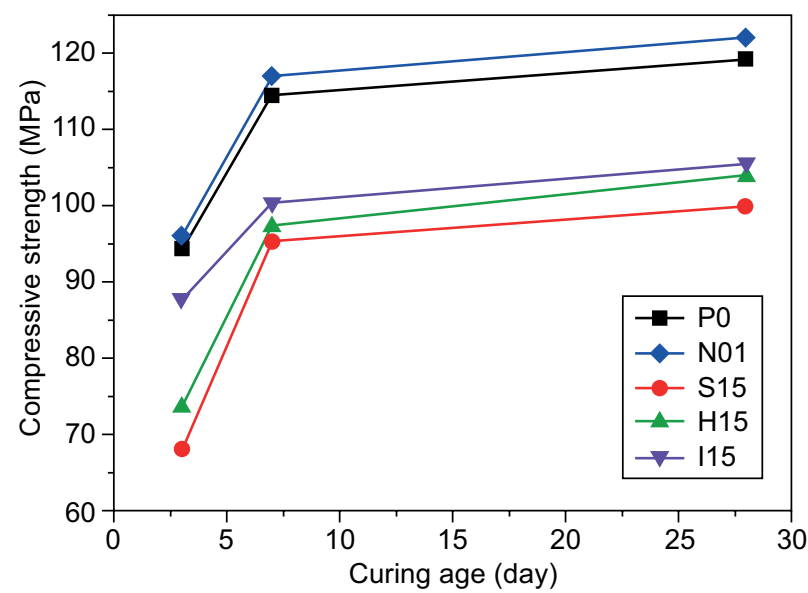

Figure 1. The compressive strength development of the MOC pastes. be more effective in the pozzolanic reaction than silica fume [26]. Thus, the addition of nano-silica can promote the pozzolanic reaction in the silica fume, too. This will also contribute to the higher compressive strength of I15 over S15 and H15. Although high volume silica fume introduces the advantage of increasing the workability of the cementitious materials, its slow earlyage strength gain is a major drawback and has hindered its application, as shown in Figure 1 (S15). Then, the shortcoming of the nano-silica modified cement-based material is that the nano-silica adversely affects its workability due to the high specific surface area [27]. In considering the characteristics of the constituents (silica fume, phosphoric acid, and nano-silica), the benefit of each material can help counteract the shortcomings of the other: active nano-silica can improve the early-age mechanical properties while silica fume and phosphoric can improve the flowability.

\section{Water resistance}

Water resistance is one of the most important factors to evaluate the performance of MOC and can largely affect the application scope and field in MOC. Figure 2 shows the compressive strength retention of the MOC pastes after immersion for 28-day and 56-day in water. As can be clearly seen, the compressive strength retention of the nano-silica MOC (N01) and neat MOC (P0) are only $15.08 \%$ and $14.70 \%$ at 28 -day immersion. This demonstrates that the incorporation of a single nano-silica has no obvious positive effect on the water resistance in the MOC. The reason may be due to the low content of active silica for incorporation of $1 \%$ nanosilica in the MOC that has little effect on the pozzolanic reaction. The addition of silica fume has a positive effect on the water resistance of MOC with the strength retention of $44.04 \%$ after 28-day immersion (Figure 2). But there is a $55.96 \%$ loss in strength retention. Then the further addition of phosphoric acid has a more obvious positive effect on the water resistance of MOC, which has $105.40 \%$ strength retention at 28 -day immersion. Meanwhile, the strength retention maintains at higher than $80 \%$ after 56-day immersion. This indicates that the addition of phosphoric acid in the silica fume MOC is an effective method for MOC to preserve the water resistance. Besides, the nano-silica added silica fume + phosphoric acid MOC pastes exhibit the best water resistance in the five kinds of MOC when we disregard the immersion time. What is most important is that the strength retention of silica fume + phosphoric acid + nano-silica MOC (I15) are much higher in the further immersion in water for 56-days than 28-days with the strength retention of $133.70 \%$, which is $25.1 \%$ higher than the 28-day water immersion. What is more, the strength retention of $\mathrm{I} 15$ is $53.82 \%$ higher than the silica fume + phosphoric acid MOC e(H15). The results show that H15 incorporating $1 \%$ nano-silica expresss 
outstanding resistance to water and can be dramatically boosted when an appropriate amount of silica fume + phosphoric acid + nano-silica (SPN) is utilised. On the one hand, this noticeable result may be due to the water environment that provided sufficient free water that facilitated the secondary hydration of MOC that forms the more main crystal phase after the water immersion, as reported in the previous literature [28]. On the other hand, the great improvement in the water resistance of MOC with nano-silica incorporation may be due to the amorphous magnesium-chloride-silicate-hydrate ( $\mathrm{M}-\mathrm{Cl}-$ $-\mathrm{S}-\mathrm{H})$ and magnesium-chloride-hydrate gels $(\mathrm{M}-\mathrm{Cl}-\mathrm{H})$ formed by the pozzolanic reaction of the reactive $\mathrm{SiO}_{2}$ contents of silica fume and nano-silica under the alkaline condition of the MOC system. With a large surface area, the well dispersed silica fume and nano-silica particles would form a network of $\mathrm{M}-\mathrm{Cl}-\mathrm{S}-\mathrm{H}$ gel and $\mathrm{M}-\mathrm{Cl}-\mathrm{H}$ gels weaved with the microstructure of the MOC crystals. As a consequence, the water shy MOC phases would be protected to a certain extent by the surrounding spherical silica fume and nano-silica particles and water insoluble $\mathrm{M}-\mathrm{Cl}-\mathrm{S}-\mathrm{H}$ gel and $\mathrm{M}-\mathrm{Cl}-\mathrm{H}$ gels [5].

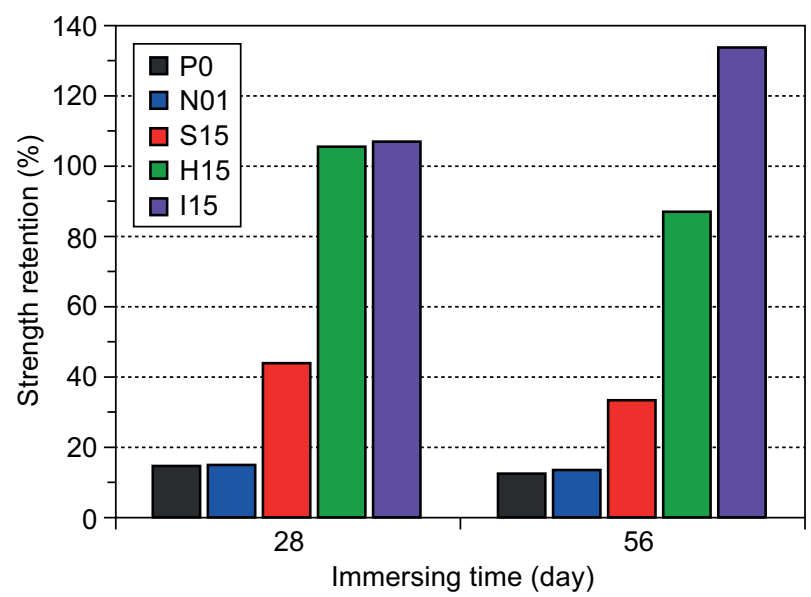

Figure 2. The compressive strength retention of the MOC pastes after immersion.

\section{Thermal stability}

During the heat process, MOC loses weight due to the gradual loss of crystalline water, structural water and $\mathrm{HCl}$. The main hydration $5 \mathrm{Mg}(\mathrm{OH})_{2} \cdot \mathrm{MgCl}_{2} \cdot 8 \mathrm{H}_{2} \mathrm{O}$ crystals lose eight crystalline water to $5 \mathrm{Mg}(\mathrm{OH})_{2} \cdot \mathrm{MgCl}_{2}$ before $215^{\circ} \mathrm{C}$, with the corresponding theoretical weight loss rate of $27.0 \%$ [29]. The thermogravimetric (TG) curves of five kinds of MOC from $25{ }^{\circ} \mathrm{C}$ to $800{ }^{\circ} \mathrm{C}$ are shown in Figures 3a-e, respectively. As can be seen from the TG curves, five kinds of MOC pastes showed a similar shape and they could be divided into three weight loss stages. The weight loss ratio of P0, N01, S15, H15 and I15 were $17.36 \%, 17.40 \%, 16.40 \%, 16.29 \%$ and $16.20 \%$ when the temperature increased from $25{ }^{\circ} \mathrm{C}$ $\sim 215{ }^{\circ} \mathrm{C}$ at the first stage, respectively. Therefore, the actual contents of Phase 5 are $64.30 \%, 64.44 \%$, $60.00 \%, 60.33 \%$ and $60.74 \%$ in P0, N01, S15, H15 and I15 after 28 days of curing, respectively. This is in good accordance with the compressive strength development of the five types of MOC.

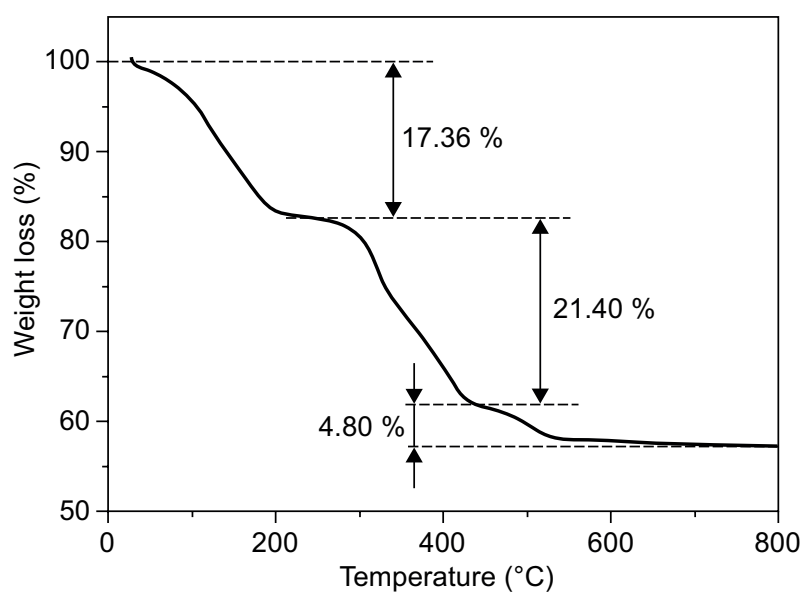

a) $\mathrm{P0}$

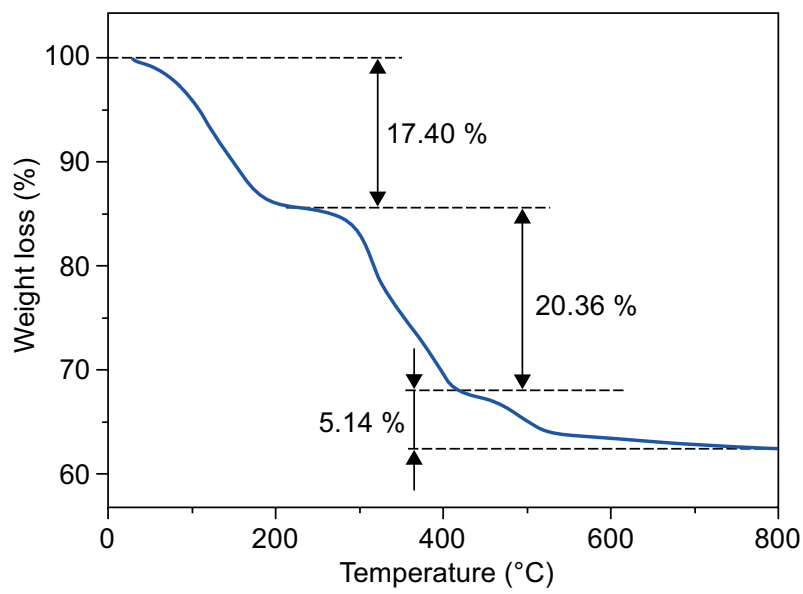

b) N01

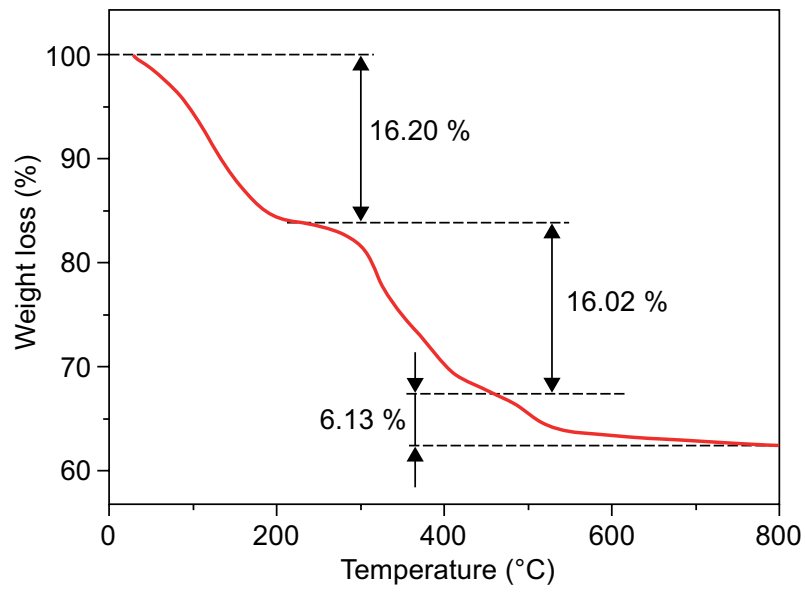

c) $\mathrm{S} 15$

Figure 3. The TG curves of the MOC pastes at 28 days. (Continue on next page) 


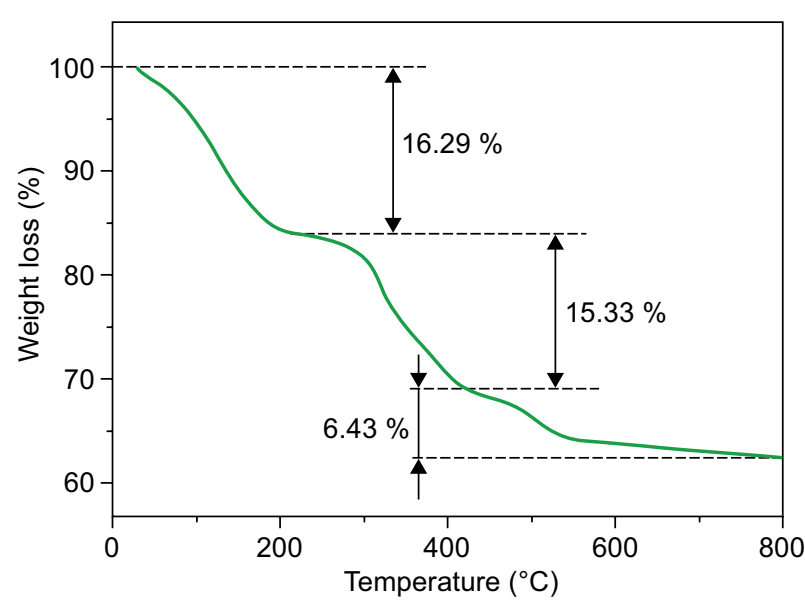

d) $\mathrm{H} 15$

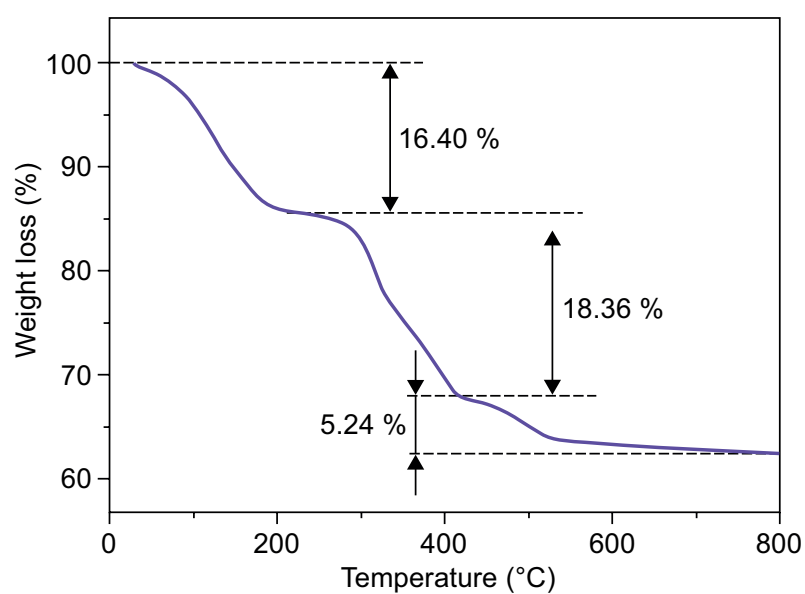

e) I15

Figure 3. The TG curves of the MOC pastes at 28 days.

\section{$\mathrm{XRD}$ analysis}

Figure 4 presents the XRD patterns of the silica fume + phosphoric acid + nano-silica MOC (I15) and the neat controlled sample (P0). It is interesting to notice that no new crystalline phase is observed after adding SPN, which means the products that improve the water resistance of MOC are amorphous in nature. It can be seen that the main crystallised hydration product of MOC is Phase 5, irrespective of whether the additives are added or not. Phase 5 is the most important crystal phase that affects the mechanical strength of MOC [5, $6]$. It is worth noting that the percentage of non-reacted $\mathrm{MgO}$ increased and the percentage of Phase 5 decreased after the addition of SPN compared to the controlled cement from the XRD pattern peaks (I15-1 and P0-1). This indicates the slightly low compressive strength after incorporation of the additives, which is consistent with the compressive strength development (Figure 1). After being soaked in water, the percentage of the Phase 5 increased with the immersion time increase. Meanwhile, the percentage of non-reacted $\mathrm{MgO}$ reduced steadily after water immersion. Additionally, there

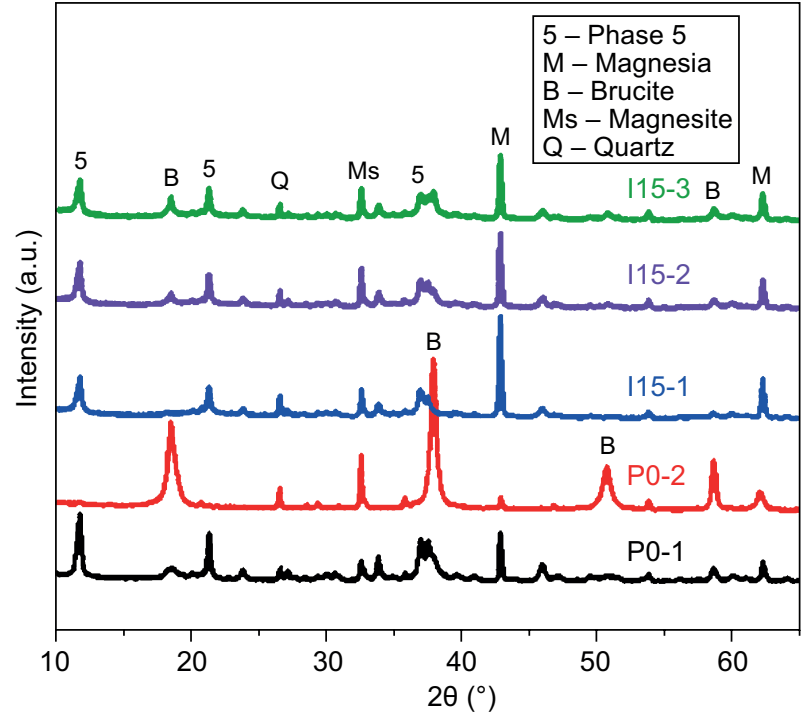

a)

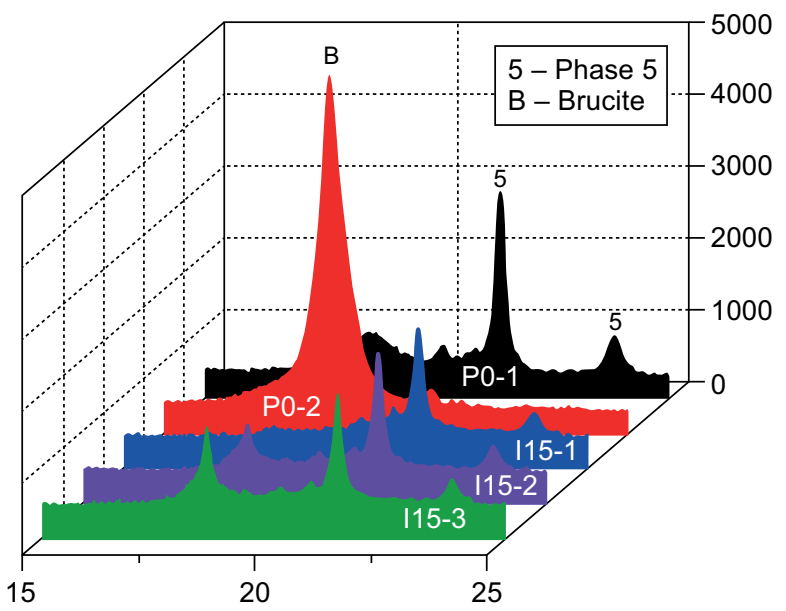

b)

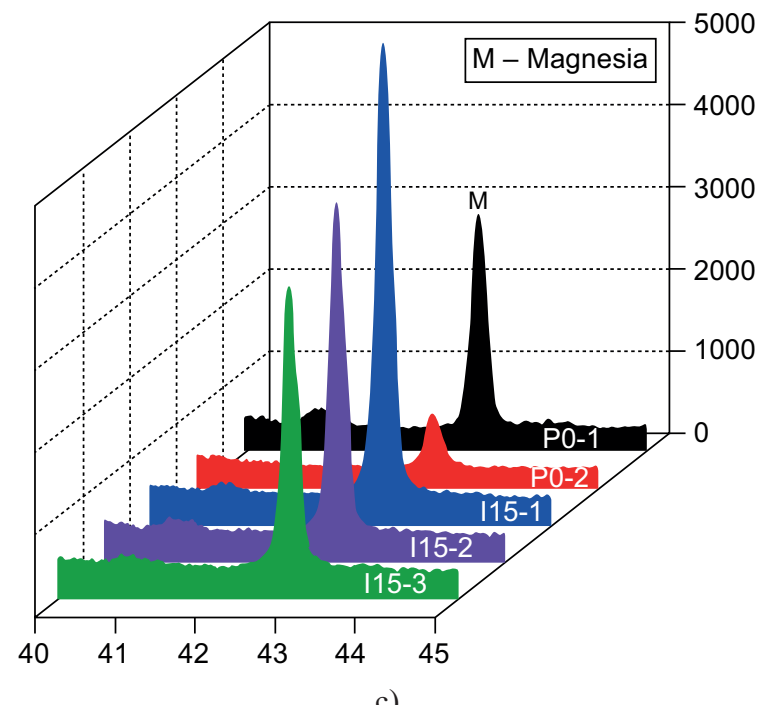

c)

Figure 4. The XRD patterns of the MOC after air curing and water immersion (I15-1 and P0-1: air curing for 28-days; I15-2 and P0-2: water immersion for 28-days; I15-3: water immersion for 56-days; b and c: the interval graphs) 
exists some percentage of brucite in the I15 cement after being soaked in water and the percentage slightly increased with the increased soaking time. The two results demonstrate that a secondary hydration process happened in the MOC after water immersion for some of the non-reacted $\mathrm{MgO}$ reacted to the Phase 5 and a small amount reacted to the brucite. However, the primary reaction may be the reaction to generate Phase 5 that contributes to the excellent resistance to water. Thus, the XRD patterns confirmed that the high, water absorption of the phosphoric acid and nano-silica, which allow less water available for hydration, thus, it retards the crystal growth in the MOC, which is keeping with the development of the compressive strength and strength retention. Therefore, when soaked in water, the water is sufficiently provided, thus, it promotes the secondary hydration in the MOC. But the percentage of brucite in I15 is much lower compared to P0-1. It is understood that the MOC phases (Phase 3 and Phase 5) are not stable in water and would decompose into brucite after a sustained period of exposure to water. If the formation of brucite was limited, then the rate of decomposition would be at least postponed, if not totally prevented. Consequently, the inhibitability of brucite growth by SPN could also be attributed to the enhancement of the water resistance of the MOC.

\section{SEM images}

The typical morphology of the hardened and immersed MOC is shown in Figure 5. Apparently, the controlled MOC is covered with a gel-like crystal in the substrate and needle-like crystals in the pores accompanied by some cracks (Figure 5e). However, the I15 cement exhibited all gel-like crystals on the surface and a more compact structure than the controlled paste (Figure 5c). But the surface presented large crisscross cracks. This implies the lower compressive strength of I15 cement than the controlled paste. On the one hand, the obvious cracks may be due to the water absorption of $\mathrm{H}_{3} \mathrm{PO}_{4}$ and nano-silica that lead to inadequate water retention/hydration in the $\mathrm{I} 15$ cement, thus, results in the easy generation of cracks [30]. It is significant to find that the number of cracks reduced after immersion in the water. The cracks decreased perhaps due to the reduction content of the excess $\mathrm{MgO}$. On the other hand, the further addition of nano-silica in H15 (I15) increased the hydration heat rate and total hydration heat that also attributed to the formation of cracks in I15 (Figure 6). What is more, the substrates both overlapped the gellike crystals and formed a much denser interlocking network than the air cured paste and controlled sample (all covered with flocculent brucite crystals). This result means that the nano-silica could active the silica fume to react with MOC to generate an amorphous product, which was stable in water and protected the hydration product from decomposition. The reduced cracks and generated amorphous product contributed to the eminent resistance of MOC after water immersion. At the same time, the EDS indicated the existence of $\mathrm{M}-\mathrm{Cl}-\mathrm{S}-\mathrm{H}$ gels and $\mathrm{M}-\mathrm{Cl}-\mathrm{H}$ gels in the surface. The results of these examinations indicate that the nanoscale $\mathrm{SiO}_{2}$ behaves

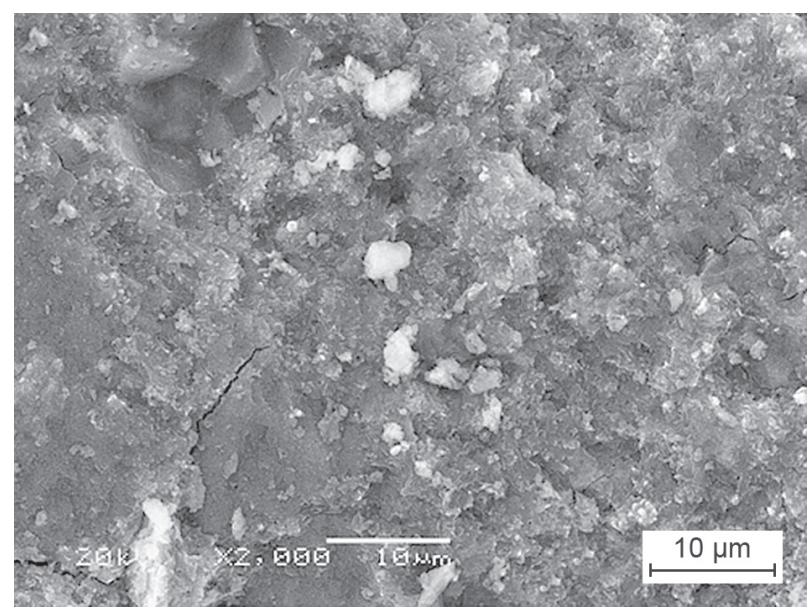

a) $\mathrm{I} 15-3$

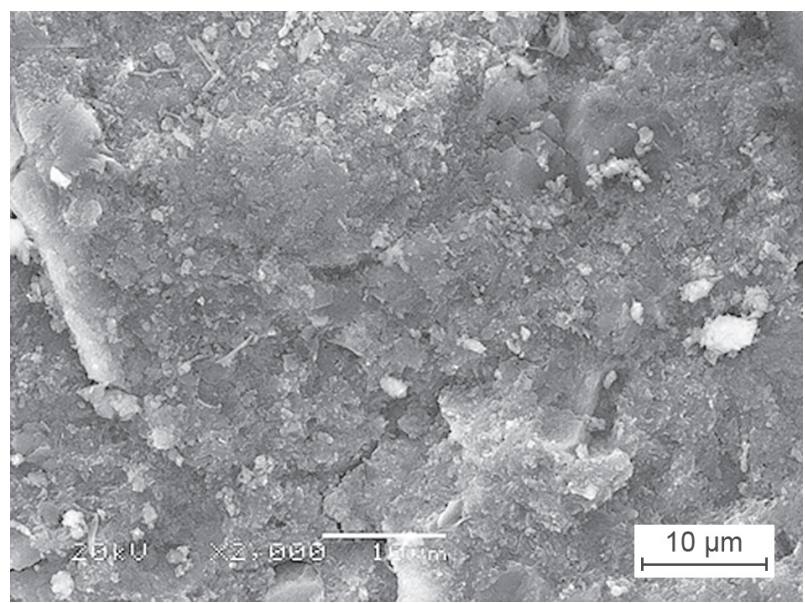

b) $\mathrm{I} 15-2$

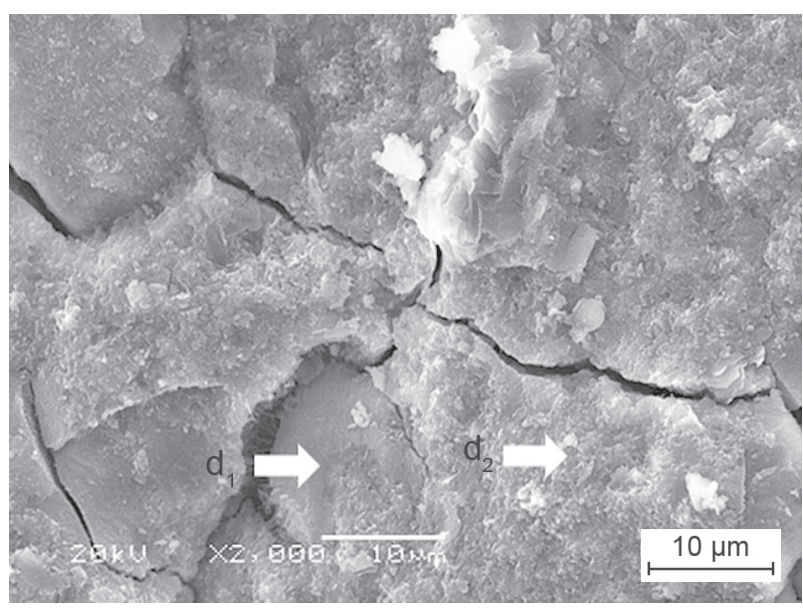

c) $115-1$

Figure 5. The SEM images of the MOC pastes cured in air and after immersion (I15-1 and P0-1: air curing for 28-days; I15-2 and P0-2: water immersion for 28-days; I15-3: water immersion for 56-days). (Continue on next page) 
not only as a filler to improve the microstructure, but also as an activator to promote the pozzolanic reaction [31]. The improved water resistance and reduced cracks
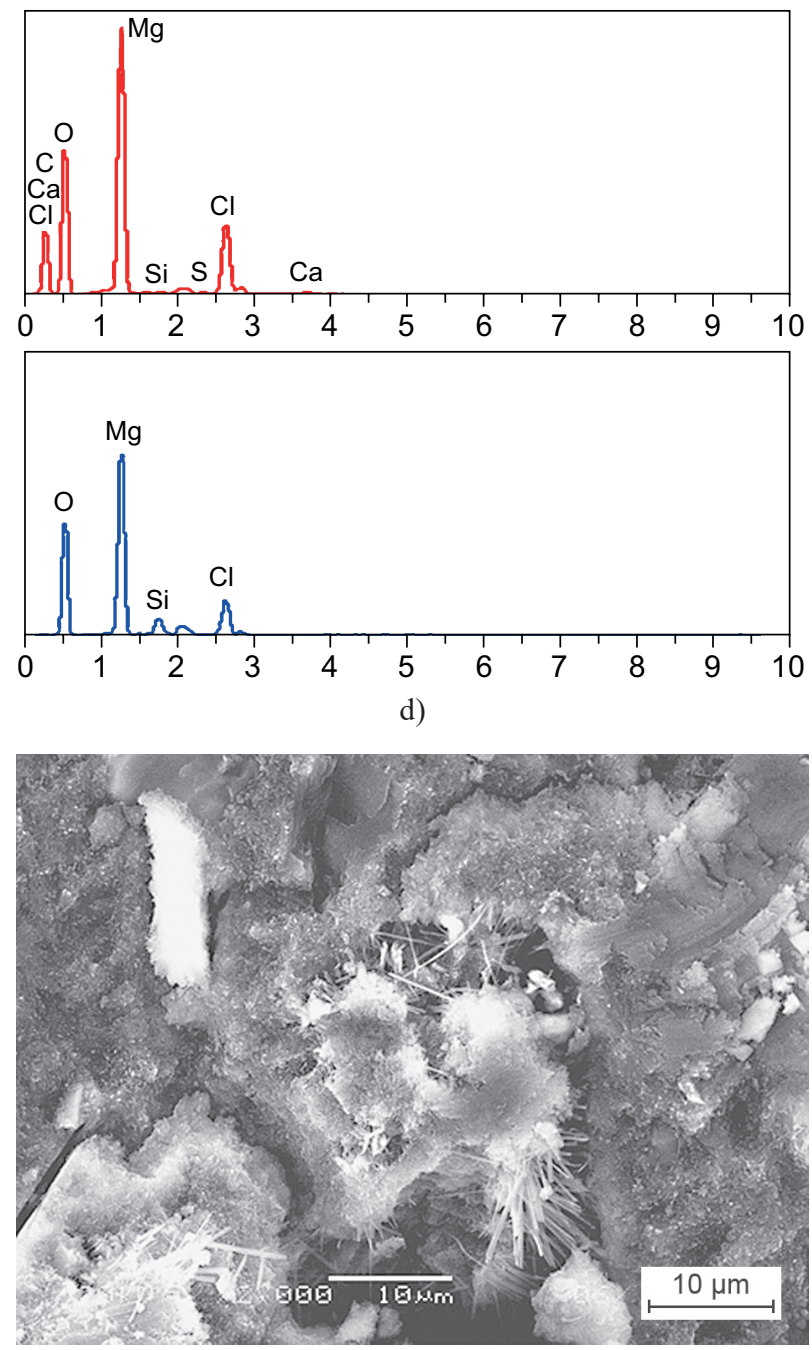

e) $\mathrm{P} 0-1$

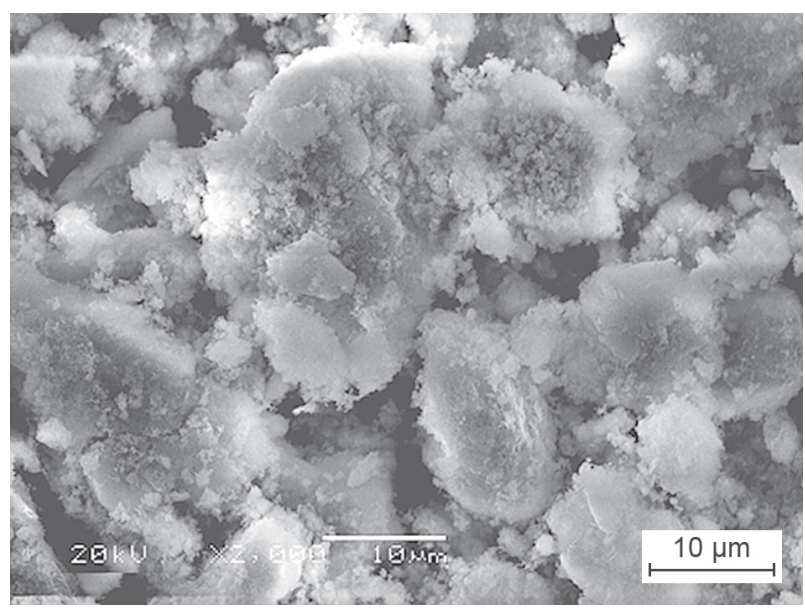

f) $\mathrm{P} 0-2$

Figure 5. The SEM images of the MOC pastes cured in air and after immersion (I15-1 and P0-1: air curing for 28-days; I15-2 and P0-2: water immersion for 28-days; I15-3: water immersion for 56-days). is directly related to the decrease in $\mathrm{MgO}$ content of the pastes and the improved stability of Phase 5 in water. The results from the SEM images suggest that nanosilica and silica fume can act as a source of soluble $\mathrm{Si}$ which results in the formation of an amorphous ( $\mathrm{M}-\mathrm{Cl}-$ $\mathrm{S}-\mathrm{H})$ type cementitious gel. The gel formed could help improve the Phase 5 stability in water by interlocking mechanisms which impede the access of water to the Phase 5.

It was reported that the gel-like morphology is beneficial in improving the water resistance [32]. The reason is that the existence of a gel-like morphology reduces the porosity of the hardened paste and the hardened specimens become so compact that they can prevent water from permeating easily [30, 32]. MIP is a general method to test the porosity and pore size distribution of porous materials such as cement based materials [33]. The total intruded volume, total porosity, pore volume distribution, permeability coefficient and specific surface are tabulated in Table 3. Meanwhile, the pore volume distribution curves of the MOC are presented in Figure 7. It can be seen that the incorporation

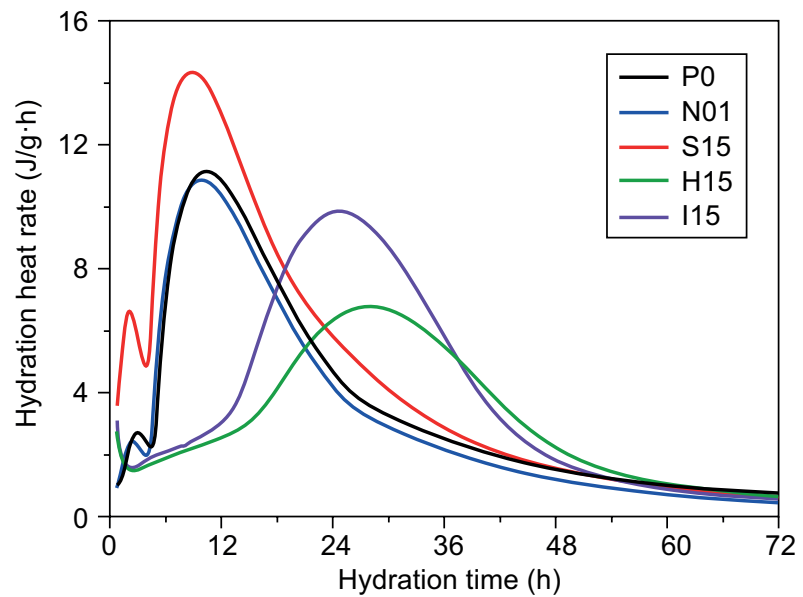

a)

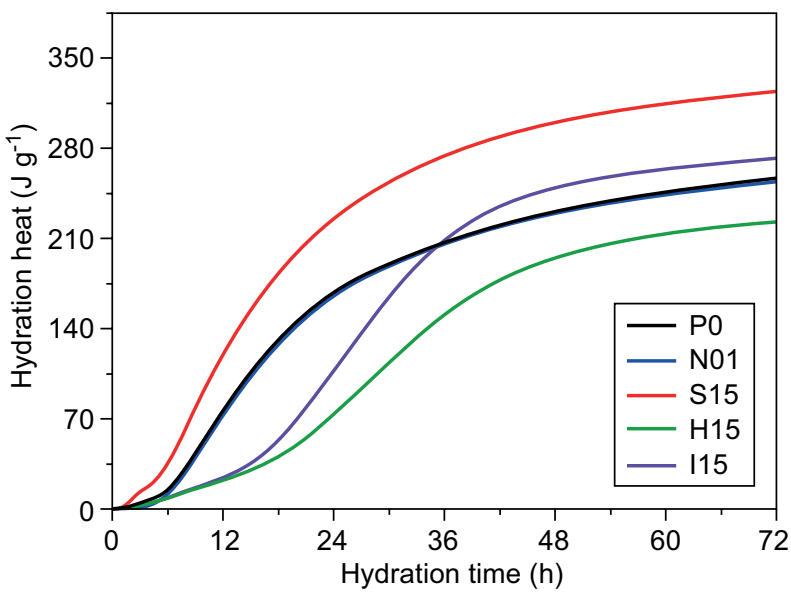

b)

Figure 6. The kinetics heat curves of the MOC pastes: a) hydration heat rate and $b$ ) hydration heat. 
of additives increases the total porosity, except for the addition of nano-silica. For instance, the total porosity increases by $2.07 \%, 25.33 \%$, and $12.28 \%$ in S15, $\mathrm{H} 15$ and $\mathrm{I} 15$ in the comparison to P0, respectively. The increased total porosity of I15 is consistent with the obvious cracks shown in the images. Nevertheless, the total porosity of N01 and I15 decreases by $15.07 \%$ and $10.41 \%$ when compared with $\mathrm{P} 0$ and $\mathrm{H} 15$, respectively. The change of total porosity and surface area are in accordance with the compressive strength development in the MOC after 28 days of air curing. From Figure 7, we can find that the incorporation of additives clearly fills the large pores $(>0.1 \mu \mathrm{m})$, especially for the single addition of silica fume and nano-silica. The further addition of $\mathrm{H}_{3} \mathrm{PO}_{4}$ in $\mathrm{S} 15$ increases the large pores as shown in Figure 7. Then the further addition of nanosilica in $\mathrm{H} 15$ decreases the large pores. The change in the large pore volume proportion is not directly related to the water resistance development of the MOC before water immersion. This phenomenon means that pore structure of the MOC has less of an effect on the water resistance than the crystallinity of the hydration product. Additionally, the addition of additives reduces the permeability of the MOC with different extents. Among the varying additives, silica fume shows the best resistant permeability. But the water resistance of S15 is not the highest one among the five types of MOC. This indicates that the permeability is not directly relevant

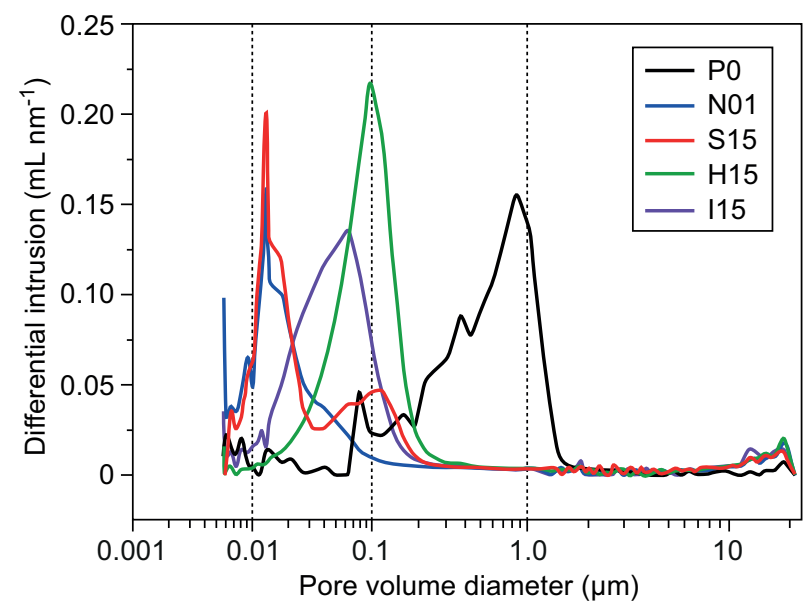

to the development of water resistance in the MOC in this experiment. At the same time, the much higher permeability of I15 may be attributed to the microcracks generated by the non-abundance of water in the hydration process during 28 days of air curing.

\section{CONCLUSION}

The effect of silica fume + phosphoric acid + nanosilica on the water resistance of MOC was investigated in this study. The incorporation of nano-silica can increase the compressive strength of MOC, which may be attributed to pozzolanic reaction. For the silica fume + phosphoric acid + nano-silica blended paste, the water resistance was remarkably improved and the strength retention increased with an increase in the water immersion time. The strength retention of the MOC increased $33.70 \%$ when immersed in water for 56 days. This great improvement is attributed to two main reasons: one is the secondary hydration to form the primary Phase 5, including $\mathrm{M}-\mathrm{Cl}-\mathrm{S}-\mathrm{H}$ gels and $\mathrm{M}-\mathrm{Cl}$ $-\mathrm{H}$ gels; The other is the postponement of the formation of brucite that sustained the main phase. Through the pore structure analysis, the water resistance of the MOC is not directly related to the change of porosity and permeability. The significant improvement of the water resistance may greatly expand the application of MOC in outdoor materials.

\section{Acknowledgements}

Funding: Financial support from the Special Projects: the Major Project for the Transformation of Scientific and Technological Achievements of Qinghai Province (grant numbers 2018-NN-152 and 2019-GX165), the Major Project for Science and Technology Development of Qinghai Province, (grant numbers 2015-GX-A1A and 2014-GX-A2A), the Natural Science Foundation of China (grant number U1507120) and the Youth Innovation Promotion Association CAS (grant numbers 2018467 and 2019423) is gratefully acknowledged.

Figure 7. The pore size distribution of the MOC.

Table 3. The total porosity and pore volume distribution after 28 days of air curing.

\begin{tabular}{|c|c|c|c|c|c|c|c|c|c|}
\hline \multirow[t]{2}{*}{ Sample } & \multirow{2}{*}{$\begin{array}{l}\text { Total intruded } \\
\text { volume }\left(\mathrm{cc} \cdot \mathrm{g}^{-1}\right)\end{array}$} & \multirow{2}{*}{$\begin{array}{c}\text { Total porosity } \\
(\%)\end{array}$} & \multicolumn{4}{|c|}{ Pore volume distribution (\%) } & \multirow{2}{*}{$\begin{array}{l}\text { Permeability } \\
\text { (md) }\end{array}$} & \multirow{2}{*}{$\begin{array}{l}\text { Bulk density } \\
\left(\mathrm{g} \cdot \mathrm{cm}^{-3}\right)\end{array}$} & \multirow{2}{*}{$\begin{array}{l}\text { Surface area } \\
\qquad\left(\mathrm{m}^{2} \cdot \mathrm{g}^{-1}\right)\end{array}$} \\
\hline & & & $>1 \mathrm{um}$ & $0.1-1 \mathrm{um}$ & $0.01-0.1 \mathrm{um}$ & $<0.01 \mathrm{um}$ & & & \\
\hline P0 & 0.1046 & 18.32 & 7.93 & 3.71 & 82.03 & 6.33 & 707.76 & 1.7518 & 17.712 \\
\hline N01 & 0.0844 & 15.56 & 11.76 & 6.54 & 68.94 & 12.76 & 512.55 & 1.8438 & 17.789 \\
\hline S15 & 0.1019 & 18.70 & 10.50 & 17.67 & 65.50 & 6.33 & 8.36 & 1.8346 & 16.711 \\
\hline H15 & 0.1276 & 22.96 & 8.93 & 48.76 & 41.67 & 0.64 & 64.19 & 1.7990 & 6.585 \\
\hline $\mathrm{I} 15$ & 0.1140 & 20.57 & 9.40 & 16.48 & 71.25 & 2.87 & 648.14 & 1.8046 & 11.070 \\
\hline
\end{tabular}


Huang Q., Wen J., Li Y., Zheng W., Chang Ch., Dong J., Man Y., Danchun A., Zhou Y., Xiao X.

\section{REFERENCE}

1. Montle J., Mayhan K. (1974): The role of magnesium oxychloride as a fire-resistive material. Fire Technology, 10(3), 201-210. Doi: 10.1007/BF02588845

2. Li G. Z., Yu Y. Z., Li J. Q., Wang Y. Z., Liu H. S. (2003): Experimental study on urban refuse/magnesium oxychloride cement compound floor tile. Cement and concrete research, 33(10), 1663-1668. Doi: 10.1016/S0008-8846(03)00136-4

3. Simatupang M. H., Geimer R. L. (1990). Inorganic binder for wood composites: feasibility and limitations. In: Proceedings of Wood Adhesive Symposium, Forest Product Resources Society, pp. 169-176.

4. Plekhanova T.A., Keriene T. A. J., Gailius A., Yakovlev G., Yakovlev I. (2007): Structural, physical and mechanical properties of modified wood-magnesia composite. Construction and Building Materials, 21(9), 1833-1838. Doi: 10.1016/ j.conbuildmat.2006.06.029

5. Chau C., Chan J., Li Z. (2009): Influences of fly ash on magnesium oxychloride mortar. Cement and Concrete Composites, 31(4), 250-254. Doi: 10.1016/j.cemconcomp.2009. 02.011

6. Li Y., Yu H., Zheng L., et al. (2013): Compressive strength of fly ash magnesium oxychloride cement containing granite wastes. Construction and Building Materials, 38, 1-7. Doi: 10.1016/j. conbuildmat.2012.06.016

7. Deng D. (2003): The mechanism for soluble phosphates to improve the water resistance of magnesium oxychloride cement. Cement and Concrete Research, 33(9), 1311-1317. Doi: 10.1016/S0008-8846(03)00043-7

8. Li Y., Li Z., Pei H., Yu H. (2016): The influence of $\mathrm{FeSO}_{4}$ and $\mathrm{KH}_{2} \mathrm{PO}_{4}$ on the performance of magnesium oxychloride cement. Construction and Building Materials, 102, 233-238. Doi: 10.1016/j.conbuildmat.2015.10.186

9. Chithra S., Kumar S., Chinnaraju K. S. (2016): The effect of colloidal nano-silica on workability, mechanical and durability properties of high performance concrete with copper slag as partial fine aggregate. Construction and Building Materials, 113, 794-804. Doi: 10.1016/j.conbuildmat.2016.03.119

10.Said A.M., Zeidan M.S., Bassuoni M.T., Tian Y. (2012): Properties of concrete incorporating nano-silica. Construction and Building Materials, 36, 838-844. Doi: 10.1016/j.conbuildmat.2012.06.044

11.Ji T. (2005) Preliminary study on the water permeability and microstructure of concrete incorporating nano-SiO . Cement $^{2}$ and Concrete Research, 35(10), 1943-1947. Doi: 10.1016/j. cemconres.2005.07.004

12.Najigivi A., Rashid S. A., Aziz F. N. A., Saleh M. A. M. (2011): Investigations on the permeability properties development of binary blended concrete with nanoSiO $\mathrm{S}_{2}$ particles. Journal of Composite Materials, 45(19), 1931-1938. Doi: 10.1177/ 0021998310389091

13.Naji Givi A., Rashid S. A., Aziz F. N. A., Saleh M. A. M (2011): The effects of lime solution on the properties of $\mathrm{SiO}_{2}$ nanoparticles binary blended concrete. Composites Part B: Engineering, 42(3), 562-569. Doi: 10.1016/j.compositesb. 2010.10.002

14.Pacheco-Torgal F., Miraldo S., Ding Y., Labrincha J.A. (2013): Targeting HPC with the help of nanoparticles: an overview. Construction and Building Materials, 38(2), 365-370. Doi: 10.1016/j.conbuildmat.2012.08.013

15.Zhang M. H., Li H. (2011): Pore structure and chloride permeability of concrete containing nano-particles for pavement. Construction and Building Materials, 25(2), 608-616. Doi: 10.1016/j.conbuildmat.2010.07.032

16.Riahi S., Nazari A. (2011): Compressive strength and abrasion resistance of concrete containing $\mathrm{SiO}_{2}$ and $\mathrm{CuO}$ nanoparticles in different curing media. Science China Technological Sciences, 54(9), 2349-2357. Doi: 10.1007/s11431-011-4463-4
17.Li H., Zhang M. H., Ou J. P. (2006): Abrasion resistance of concrete containing nanoparticles for pavement. Wear, 260(11-12), 1262-1266. Doi: 10.1016/j.wear.2005.08.006

18. Nazari A., Riahi S. (2011): The effects of $\mathrm{SiO}_{2}$ nanoparticles on physical and mechanical properties of high strength compacting concrete. Composites Part B: Engineering, 42(3), 570-578. Doi: 10.1016/j.compositesb.2010.09.025

19.Dong J. M., Yu H. F., Zhang L. M. (2010): Study on experimental conditions of hydration methods of determining active magnesium oxide content. Journal of Salt Lake Research, 18(1), 38-41.

20.Huang Q., Xiao X.Y., Li Y., et al. (2018): Research on the properties of magnesium oxychloride cement prepared with simulated seawater. Advances in Cement Research, 30(7), 277-284. Doi: 10.1680/jadcr.17.00127

21.Huang Q., Li Y., Zheng W.X., et al. (2018) Investigation on the properties of magnesium oxychloride cement prepared by seawater. Advances in Cement Research, article in press. Doi: $10.1680 /$ jadcr. 18.00159

22.Li X., Zhou Y., Zhang X., et al. (2018) Experimental investigation of thermal and mechanical properties of magnesium oxychloride cement with form-stable phase change material. Construction and Building Materials, 186, 670-677. Doi: 10.1016/j.conbuildmat.2018.07.113

23.Shih J. Y., Chang T. P., Hsiao T. C. (2006): Effect of nanosilica on characterization of Portland cement composite. Materials Science and Engineering A., 424(1), 266-274. Doi: 10.1016/j. msea.2006.03.010

24.Li H., Xiao H., Yuan J., Ou J. (2004): Microstructure of cement mortar with nanoparticles. Composites Part B: Engineering, 35(2), 185-189. Doi: 10.1016/S1359-8368(03)00052-0

25.Thomas J. J., Jennings H. M., Chen J. J. (2009): Influence of nucleation seeding on the hydration mechanisms of tri-calcium silicate and cement Journal of Physical Chemistry C., 113(11), 4327-4334. Doi: $10.1021 / \mathrm{jp} 809811 \mathrm{w}$

26. Qing Y., Zenan Z., Deyu K., et al. (2007): Influence of nano-SiO addition on properties of hardened cement paste as compared with silica fume. Construction and Building Materials, 21(3), 539-545. Doi: 10.1016/j.conbuildmat.2005.09.001

27. Sobolev K., Flores I., Hermosillo R., Torres-Martinez L. M. (2006). Nanomaterials and nanotechnology for high-performance cement composites. in: Proceedings of ACI session on nanotechnology of concrete: recent developments and future perspectives, 91-118.

28.He P. P., Poon C., Tsang D.C.W. (2017): Using incinerated sewage sludge ash to improve the water resistance of magnesium oxychloride cement. Construction and Building Materials, 147, 519-524. Doi: 10.1016/j.conbuildmat.2017.04.187

29.Xia, S, Xing, P, Gao S. (1991): Study on the basic compounds of magnesia cement-the thermal-behavior of magnesium oxychlorides. Thermochimica Acta, 183, 349-363. Doi: 10.1016/ 0040-6031(91)80471-T

30.Tan Y., Liu Y., Grover L. (2014): Effect of phosphoric acid on the properties of magnesium oxychloride cement as a biomaterial. Cement and Concrete Research, 56, 69-74. Doi: 10.1016/j.cemconres.2013.11.001

31.Jo B. W., Kim C. H., Tae G., et al. (2007): Characteristics of cement mortar with nano-SiO $\mathrm{S}_{2}$ particles. Construction and Building Materials, 21(6), 1351-1355. Doi: 10.1016/j.conbuildmat.2005.12.020

32.Lu H., Wang P., Jiang N. (1994): Design of additives for water-resistant magnesium oxychloride cement using pattern recognition. Materials Letters, 20(3-4), 217-223. Doi: 10.1016/ 0167-577X(94)90090-6

33.Jiang C., Fan K., Wu F., et al. (2014): Experimental study on the mechanical properties and microstructure of chopped basalt fibre reinforced concrete. Materials \& Design, 58, 187-193. Doi: 10.1016/j.matdes.2014.01.056 